IBIMA Publishing

Journal of Radiology Research and Practice

http://www.ibimapublishing.com/journals/RADI/radi.html

Vol. 2015 (2015), Article ID 819260, 8 pages

DOI: $10.5171 / 2015.819260$

Research Article

\title{
Developmental Alterations of Teeth in Young Patients
}

\author{
Constantino Ledesma-Montes ${ }^{1}$, Maricela Garcés-Ortíz ${ }^{2}$, Juan Francisco Salcido- \\ García ${ }^{3}$ and Florentino Hernández-Flores ${ }^{4}$ \\ ${ }^{1,2}$ Clinical Oral Pathology Laboratory. División de Estudios de Posgrado e Investigación. Facultad de \\ Odontología, UNAM. México, MÉXICO
}

${ }^{3}$ Oral Diagnosis Clinic. División de Estudios de Posgrado e Investigación. Facultad de Odontología, UNAM. México, MÉXICO

${ }^{4}$ Oral Surgery Clinic. División de Estudios de Posgrado e Investigación. Facultad de Odontología, UNAM. México, MÉXICO

Correspondence should be addressed to: Constantino Ledesma-Montes; cledezma@unam.mx.

Received date: 11 March 2014; Accepted date: 4 June 2014; Published date: 2 February 2015

Academic Editor: Anja Baraba

Copyright (C) 2015. Constantino Ledesma-Montes, Maricela Garcés-Ortíz, Juan Francisco Salcido-García and Florentino Hernández-Flores . Distributed under Creative Commons CC-BY 4.0

\begin{abstract}
Research motivation: The objective of this study was to know the frequency of dental developmental alterations in Mexican children and adolescents attending the Stomatological Clinics of the Faculty of Dentistry of the Universidad Nacional Autónoma de México. Research design/methodology: The files of the patients attended in our institution were reviewed and 128 were from patients among 2 and 18 years old with dental developmental alterations were selected. Data on diagnosis, age, gender and involved tooth were analyzed by Students T test and $\mathrm{p}<0.05$ was considered significant. Main findings: The most frequent dental developmental alterations were: supernumeraries, missing teeth and fused teeth. Other entities were also found. Prevalence of dental alterations in the sample was $29.8 \%$ and 217 dental alterations were diagnosed. Of 217 teeth, 83.4\% were permanent and 16.6\% were deciduous teeth. Implications: Data obtained from this study will address the consciousness of the authorities and personnel of the institutions involved in providing health services on the importance to conduct imagenologic studies in children and adolescent population for early recognition of the intrabony pathological conditions.
\end{abstract}

Keywords: Dental developmental alterations, hipodoncia, supernumerary teeth, fused teeth, microdontia.

Cite this Article as: Constantino Ledesma-Montes, Maricela Garcés-Ortíz, Juan Francisco Salcido-García and Florentino Hernández-Flores (2015)," Developmental Alterations of Teeth in Young Patients ", Journal of Radiology Research and Practice, Vol. 2015(2015), Article ID 819260, DOI: 10.5171/2015.819260 


\section{Introduction}

Dental anomalies comprise a group of dental disturbances resulting from ill-development of the dental hard tissues. Some of them could develop during tooth intraosseous formation, in other instances they are congenital or they are acquired during the postnatal life. Also, they can be seen affecting a single tooth, can affect several teeth or can be associated to systemic conditions or syndromes.

The knowledge of the frequency of dental anomalies in different populations offers important information for studies on genetic and evolutionary issues. Also, it is well known that ill-developed teeth may produce problems in occlusion, size of dental arches, esthetic inconveniencies; caries, periodontal disease and early diagnosis will importantly impact the orthodontic treatment.

Developmental alterations of teeth are entities rarely found in the Stomatological practice. These alterations are classified as alterations of the number, shape, size and structure (Neville et al, 2002). It is also known that studies in different populations presented different results. These inconsistencies may be due to different factors as: size of the sample, ethnicity, sampling method employed, and even, differences in diagnostic criteria. Also, it should be taken in count if the sample comes from a dental institution, as university, private practice or a medical clinic. For the above mentioned reasons, previously published results coming from different sources and populations should be carefully taken into account and carefully analyzed.

There are several studies on the frequency of dental developmental alterations in different populations. Some of them were done in patients attending institutional Dental Clinics (Leco-Berrocal et al, 2007; Altug-Atac and Erdem, 2007; Fernández-Montenegro et al, 2006; Endo et al, 2006; Szepesi et al, 2006; Ledesma-Montes et al, 2004; Salcido-García et al, 2004; ) or in isolated studies (Cho, 2006; Milano et al, 1999). Findings from different studies varied widely depending on the method employed, patient's age, and country and ethnic group of origin.

The aim of this study was to know the clinico-radiological features of the developmental alterations of teeth in young patients attending the Stomatological Clinics of the Postgraduate and Research Division of the Facultad de Odontología, Universidad Nacional Autónoma de México in Mexico City. Results from this study will induce health providers to conduct more imagenologic studies in this kind of population for early recognition of these entities.

\section{Material and Methods}

This study was an observational, descriptive, retrospective, longitudinal and crosssectional study. The panel of the Oral Diagnosis Clinic of the División de Estudios de Posgrado e Investigación, Facultad de Odontología, UNAM in Mexico City reviewed the panoramic radiographs of all the patients attended and separated all cases in children and adolescents showing any radiographic change. These radiographs were taken as part of the oral and medical diagnostic routine methodology made to all patients seeking stomatological attentions in our institution. Patients included in this study were those attended during the academic period of eight months; the first author was Guest Professor in that clinic. An oral and maxillofacial review made by specially trained students who were in the last year of the DDS training was made to all the patients. All the reviewers were previously calibrated and re-calibrated each two months. This calibration was done using images of the entities included in the study and more others from common and uncommon entities of the oral and maxillofacial area. This review consisted in a careful observation and palpation of the soft and hard head tissues of the head and neck area including tissues of the oral cavity. All patients or parents signed 
a Letter of Consent consenting that their clinical or microscopic data can be used for research. All the selected radiographs were reviewed in a negatoscope with a $7 \mathrm{X}$ adapted lens and discussed. In selected cases, when radiographic images were not clear or better definition of the images was necessary, dento-alveolar (periapical) and occlusal radiographs were made. Clinico-radiographic criteria applied for diagnosis was that of Neville et al (2002).

Data on age, gender, radiographic features, location and number of lesions were stored in the Microsoft Excel program, and Student's $\mathrm{T}$ test was applied to the obtained data ( $p<0.05$ was considered significant).

\section{Results}

Of the 1075 reviewed files, 430 corresponded to children and adolescent patients (4\%). Of them, 128 patients $(29.8 \%)$ showed clinical or radiographic findings of developmental alterations in their teeth (Table 1). Eleven different dental developmental alterations were diagnosed in 217 teeth. Of them, 36 were of the primary dentition $(16.6 \%)$ and 181 were permanent teeth $(83.4 \%)$. They were 52 males (41.9\%) and 72 females (58.1\%). Comparison of data showed statistical difference $(\mathrm{p}<0.01)$. It should be pointed out that more than $50 \%$ of the primary teeth $(20 / 36)$ found in this study were from a two years old boy with dentinogenesis imperfecta. From the analyzed sample, 117 were located in the maxillary area and 101 were mandibular teeth. The number of affected teeth per patient varied from 1 to 24 and the number of involved sites per patient was from one to four different anatomical regions. Ages of the analyzed patients varied from two to 18 years with a mean of 10.7 years. Frequency of lesions in the population studied is presented in table 1 .

\begin{tabular}{|l|c|c|c|c|}
\hline \multicolumn{5}{|c|}{ Table 1: Main Dental Developmental Anomalies Found by } \\
Gender in This Study* \\
\hline ANOMALY & MALES & FEMALES & TOTAL & $\begin{array}{c}\text { AFFECTED } \\
\text { TEETH }\end{array}$ \\
\hline SUPERNUMERARIES & 37 & 27 & 64 & 83 \\
\hline MISSING TEETH & 16 & 21 & 37 & 61 \\
\hline $\begin{array}{l}\text { OTHER DENTAL } \\
\text { ALTERATIONS }\end{array}$ & 9 & 18 & 27 & 74 \\
\hline TOTAL & 62 & 66 & 128 & 218 \\
\hline
\end{tabular}

*Several patients with more than one affected tooth.

\section{Supernumerary Teeth}

We found 83 supernumerary teeth (ST) in 60 patients (31.1\% of the whole sample). ST was more common in females $(n=34 ; 56.7 \%)$ than in males $(n=26 ; 43.3 \%)$ but no statistical difference was found $(p>0.05)$. Age range was among 3 and 18 years with a mean age of 9.5 years. The most common supernumerary tooth was mesiodens $(n=38$; $45.8 \%$ ) followed by bicuspids: mandibular ones were 23 cases $(27.7 \%)$ and maxillary bicuspids were 3 teeth $(3.6 \%)$ and lateral incisors were 8 teeth (9.6\%). Only the 
comparison among data of the different alterations and mesiodens was statistically significant $(\mathrm{p}<0.05)$. From all the supernumeraries, 46 were maxillary teeth and 37 were located in the mandible. Frequency of supernumerary teeth is shown in table 2.

Table 2:Relative frequency of supernumerary teeth (ST) and gender*

\begin{tabular}{|l|l|l|l|}
\hline Teeth & Male & Female & $\begin{array}{l}\text { Affected } \\
\text { teeth }\end{array}$ \\
\hline Mesiodens & 21 & 12 & 38 \\
\hline Bicuspids & 8 & 5 & 26 \\
\hline Maxillary & 1 & 2 & 3 \\
\hline Mandibular & 7 & 5 & 23 \\
\hline Lateral incisors & 4 & 3 & 8 \\
\hline Maxillary & 3 & 1 & 4 \\
\hline Mandibular & 1 & 2 & 3 \\
\hline Primary & 0 & 1 & 1 \\
\hline Paramolars & 1 & 1 & 3 \\
\hline $4^{\text {th }}$ molar & 1 & 1 & 2 \\
\hline Molars & 0 & 1 & 2 \\
\hline Canine & 1 & 1 & 4 \\
\hline
\end{tabular}

*Several patients with more than one supernumerary.

\section{Dental Agenesia}

We found 61 missing teeth $(28.1 \%$ of the analyzed sample) in 37 patients (28.9\%). 40 were maxillary teeth and 43 were located in the mandible. Missing teeth were more common in females $(n=20 ; 54 \%)$ than in males $(n=17 ; 46 \%)$. Comparing ages among genders showed no statistical significance $(p>0.05)$. Age range of the patients was among 4 and 18 years with a mean age of 9 years. The most commonly missing teeth were maxillary lateral incisors $(n=23 ; 38.3 \%)$ followed by maxillary bicuspids $(n=17$; $28.3 \%$ ) and mandibular bicuspids $(n=10$; 18.3\%). Comparison among the data above showed statistical significance $(\mathrm{p}<0.05)$. Maxillary missing teeth $(n=42 ; 68.9 \%)$ were more frequently found than mandibular missing teeth $(n=19 ; 31.1 \%)$; statistical significance was $\mathrm{p}<0.05$. Interestingly, one female patient presented 12 teeth (LedesmaMontes et al, 2012). Relative frequency of missing teeth is shown in table 3 .

Table 3: Relative frequency of missing teeth and gender*

\begin{tabular}{|l|l|l|l|}
\hline Teeth & Male & Female & $\begin{array}{l}\text { Affected } \\
\text { teeth }\end{array}$ \\
\hline $\begin{array}{l}\text { Maxillary lateral } \\
\text { incisors }\end{array}$ & 11 & 7 & 22 \\
\hline Maxillary bicuspids & 4 & 7 & 17 \\
\hline Mandibular bicuspids & 5 & 3 & 10 \\
\hline $\begin{array}{l}\text { Mandibular lateral } \\
\text { incisors }\end{array}$ & 1 & 2 & 3 \\
\hline
\end{tabular}




\begin{tabular}{|l|l|l|l|}
\hline $\begin{array}{l}\text { Mandibular central } \\
\text { incisors }\end{array}$ & 2 & 0 & 3 \\
\hline Primary teeth & 2 & 2 & 4 \\
\hline Canines & 0 & 1 & 2 \\
\hline
\end{tabular}

*Several patients with more than one missing tooth.

\section{Other Dental Alterations}

During the review of the radiographic material of the analyzed files, we found other less common developmental dental alterations. They were 9 entities in 27 patients and 74 teeth. 28 were maxillary teeth and 46 were located in mandible. Frequency of these entities in the analyzed files is shown in table 4 .

Table 4: Relative frequency of other dental alterations and gender*

\begin{tabular}{|l|l|l|l|}
\hline ENTITY & Male & Female & $\begin{array}{l}\text { Affected } \\
\text { teeth }\end{array}$ \\
\hline Fusion & 3 & 3 & 14 \\
\hline Microdontia & 2 & 5 & 10 \\
\hline Taurodontism & 0 & 2 & 4 \\
\hline Dislaceration & 0 & 4 & 4 \\
\hline Enamel pearl & 1 & 1 & 4 \\
\hline $\begin{array}{l}\text { Dentinogenesis } \\
\text { imperfecta }\end{array}$ & 1 & 0 & 24 \\
\hline Permanent & 1 & 0 & 4 \\
\hline Deciduous & 1 & 0 & 20 \\
\hline Ectopic tooth & 0 & 2 & 3 \\
\hline Macrodontia & 1 & 1 & 2 \\
\hline Supernumerary root & 1 & 0 & 1 \\
\hline Total & 9 & 17 & 43 \\
\hline
\end{tabular}

*Several patients with more than one alteration.

They were more commonly diagnosed in females $(n=17 ; 67 \%)$ than in males $(n=10$; $33 \%$ ). Comparison of data gave statistical significance $(p<0.05)$. Age range of these patients was among 2 and 16 years with a mean age of 7.9 years. Surprisingly, in this group of dental developmental alterations, primary dentition was the most commonly affected ( $n=31$ teeth; $41.9 \%$ of this group and $14.3 \%$ of the whole sample), followed by permanent lateral incisors $(n=11 ; 14.8 \%)$, molars $(n=8 ; 10.8 \%)$ and bicuspids $(n=7$; $9.5 \%$ ). In this group of dental developmental alterations, dentinogenesis imperfecta involved 24 teeth $(32.4 \%$ of this group and $11.1 \%$ of the whole sample), followed by fused teeth $(\mathrm{n}=14 ; 18.9 \%$ of this group and $6.4 \%$ of the whole sample) and microdontia $(n=10 ; 13.5 \%$ of this group and $4.6 \%$ of the whole sample). Taurodontism, dislaceration and enamel pearls were 4 cases each $(5.4 \%$ of this group and $1.8 \%$ of the whole sample respectively). Dental fusion affected more frequently anterior deciduous teeth $(n=8$; $10.8 \%$ of this group, $3.7 \%$ of the whole 1 sample and $57.7 \%$ of fused teeth) and mandibular anterior teeth $(n=10 ; 13.5 \%$ of this group, $4.6 \%$ of the whole sample and $71.4 \%$ of all the fused teeth). The more frequently found microdont was lateral incisor $(\mathrm{n}=8 ; 10.8 \%$ of this group, $3.7 \%$ of the whole sample and $80 \%$ of the 
microdonts). All taurodonts were upper $1^{\text {st }}$ molars, dislacerated roots were seen more commonly in bicuspids $(n=3 ; 4 \%$ of this group and $1.4 \%$ of the whole sample and
$75 \%$ of the dislacerated teeth) and all enamel pearls were in mandibular molars.

In table 5, entities affecting primary teeth by gender are found.

Table 5: Primary teeth with developmental alterations.

\begin{tabular}{|c|c|c|}
\hline Alteration & Tooth & Sex \\
\hline Supernumerary & 62 & Female \\
\hline \multirow{5}{*}{ Fusion } & $61-62$ & Male \\
\hline & $71-72$ & Female \\
\hline & $81-82$ & Female \\
\hline & $72-73$ & \multirow{2}{*}{ Male } \\
\hline & $82-83$ & \\
\hline Microdontia & 62 & Male \\
\hline \multirow{4}{*}{ Hipodontia } & 82 & Female \\
\hline & 62 & Male \\
\hline & 83 & Male \\
\hline & 62 & Female \\
\hline $\begin{array}{l}\text { Dentinogenesis } \\
\text { imperfecta }\end{array}$ & $\begin{array}{l}\text { From 55-65 } \\
\text { and 75-85 }\end{array}$ & Male \\
\hline
\end{tabular}

\section{Discussion}

The most frequent entities found in this study were supernumeraries followed by missing teeth. ST was the most common dental developmental abnormality we found in this study. It is well known that the frequency of ST varies among $0.28 \%$ (Fernández-Montenegro et al, 2006) to $1.53 \%$ (Gabris et al, 2006). As it was in other studies (Fernández-Montenegro et al, 2006; Ledesma-Montes et al, 2012a; Salcido-García et al 2004; Altug-Atac et al, 2007; Gábris, 2006), mesiodens was the most commonly found ST. In distinction, Leco-Berrocal et al (2007) found that the most common ST was the fourth molar. Also, in the study by Yusof and Awang (1990), it was reported that bicuspids were the most common supernumerary, and Nazif et al (1983) found that molars were the most frequently found ST.
In this study, missing teeth rated in second place. In previously reported literature, the frequency of hypodontia varied from 0.1 to 10.1\% (Flores-Mir, 2006; Hunstadbraten, 1973). As it was reported previously and as in our study, the most common missing tooth was the maxillary lateral incisor, followed by bicuspids (Szepesi, 2006; Altug-Atac, 2007; Gábris, 2006). In contrast, other studies reported that bicuspids were the most common missing teeth (Bergendal et al, 2006). As in other studies, we found deciduous missing teeth, a rarely encountered finding (Ledesma-Montes et al, 2012a; Cho, 2006).

A report dealing on root dilaceration published by Sacal et al (2001) informed that $20 \%$ of the analyzed children presented this developmental anomaly. These data contrast with our finding of only four cases. The frequency of fused teeth is very low and varies from 0.19 to $1.9 \%$ (Altug-Atac and 
Erdem, 2007; Onyeaso and Onyeaso, 2006), and the data regarding fused teeth in our study were higher since they were $4.3 \%$ of the whole sample and the third more frequent diagnosed entity. It is important to have a close follow-up with these patients in order to prevent future problems during exfoliation of the fused teeth and eruption of the succedaneous one (Ledesma-Montes et al, 2012a).

Limitations of this kind of studies are: the size of the sample, ethnicity of the population studied and that their results represent a fraction of the population attended in the institution. In another order of ideas, results from this study will improve knowledge of the dental developmental alterations in this population, increasing early diagnosis and treatment of these anomalies.

\section{Conclusion}

Data from this study differ from information contained in previously published papers. This may be attributed to differences in the ethnicity of the population studied. Also, data obtained from this study will move to address the consciousness of the authorities and personnel of the institutions involved in providing health services on the importance of conducting imagenologic studies in children and adolescent population for the early recognition of the intrabony pathological conditions. Also, data from this kind of studies will convince the authorities and health providers to conduct more imagenologic studies in order to achieve an early recognition of these entities in this group of patients.

\section{References}

1. Altug-Atac, A.T. and Erdem, D. (2007) "Prevalence and distribution of dental anomalies in orthodontic patients," American Journal of Orthodontics and Dentofacial Orthopedics, 131(4):510-514.

2. Bergendal, B., Norderyd, J., Bågesund, M. and Holst, A. (2006) "Signs and symptoms from ectodermal organs in young Swedish individuals with oligodontia," International Journal of Paediatric Dentistry, 16(5):320326.

3. Cho, S.Y. and Lee, C.K. (2006) "Congenitally missing maxillary primary canines: report of three cases," International Journal of Paediatric Dentistry, 16(6):444447.

4. Fernández-Montenegro, P., ValmasedaCastellón, E., Berini-Aytés, L. and GayEscoda, C. (2006) "Retrospective study of 145 supernumerary teeth," Medicina Oral Patología Oral Cirugía Bucal, 11(4):E339344.

5. Flores-Mir, C. (2006) "Increased hypodontia through the twentieth century," Evidence-Based Dentistry, 7(1):5.

6. Endo, T., Ozoe, R., Kubota, M., Akiyama, M. and Shimooka, S. (2006) "A survey of hypodontia in Japanese orthodontic patients," American Journal of Orthodontics and Dentofacial Orthopedics, 129(1):29-35.

7. Gábris, K., Fábián, G., Kaán, M., Rózsa, N. and Tarján, I. (2006) "Prevalence of hypodontia and hyperdontia in paedodontic and orthodontic patients in Budapest," Community Dental Health, 23(2):80-82.

8. Hunstadbraten, K. (1973) "Hypodontia in the permanent dentition," Journal of Dentistry for Children 40:115-117.

9. Leco-Berrocal, MI., Martín-Morales, J.F. and Martínez-González, J.M. (2007) "An observational study of the frequency of supernumerary teeth in a population of 2000 patients," Medicina Oral Patología Oral Cirugía Bucal, 12(2):E134-138.

10. Ledesma-Montes, C., Salcido-García, J.F., Hernández-Flores, F. and Garcés-Ortíz, M. (2012a) "Pathological findings in a sample of Mexican pediatric patients. Clinical and radiographic survey," Minerva Stomatologica, 61(5):205-212. 
11. Ledesma-Montes, C., Salcido-García, J.F., Hernández-Flores, F. and Garcés-Ortíz, M. (2012b) "Multiple supernumeraries in a non-syndromic patient," The Journal of Clinical Pediatric Dentistry, 37(2):193-198

12. Milano, M., Seybold, S.V., McCandless, G. and Cammarata, R. (1999) "Bilateral fusion of the mandibular primary incisors: report of case," ASDC Journal for Dentistry for Children, 66(4):280-282.

13. Nazif MM, Ruffalo RC, Zullo T. (1983) "Impacted supernumerary teeth: a survey of 50 cases," Journal of the American Dental Association, 106(2):201-204.

14. Neville, B.W., Dam, D.D., Allen C.M. and Bouquot, J.E. (2002) Oral \& Maxillofacial Pathology. Saunders. Philadelphia, Pa, U.S.A.

15. Onyeaso, C.O. and Oneyeaso, A.O. (2006) "Occlusal/dental anomalies found in a random sample of Nigerian schoolchildren," Oral Health and Preventive Dentistry, $4(3): 181-186$.
16. Sacal, C., Echeverri, E.A. and Keene, H. (2001) "Retrospective survey of dental anomalies and pathology detected on maxillary occlusal radiographs in children between 3 and 5 years of age," Pediatric Dentistry, 23(4):347-350.

17. Salcido-García, J.F., Ledesma-Montes, C., Hernández-Flores, F., Pérez, D. and GarcésOrtíz, M. (2004) Frequency of supernumerary teeth in Mexican population," Medicina Oral Patología Oral Cirugía Bucal, 9(5):403-409.

18. Szepesi, M., Nemes, J., Kovalecz, G. and Alberth, M. (2006) "Prevalence of hypodontia in 4-18-year-old children in the Department of Paediatric Dentistry, Faculty of Dentistry, University of Debrecen from 1999 to 2003," Fogorvosi szemle, 99(3):115119.

19. Yusof WZW, Awang MN. (1990) "Multiple impacted supernumerary teeth," Oral Surgery Oral Medicine Oral Pathology, $70(1): 126$. 